\title{
ALGUNOS ASPECTOS DEL RITMO Y DEL MOVIMIENTO NARRATIVO DEL «QUIJOTE»
}

José Ortega y Gasset y Américo Castro son los críticos que han expuesto lo esencial del dinamismo del Quijote con la mayor penetración. Por ser la orientación de ambos predominantemente ideológica, no cupo en la intención ni del uno ni del otro analizar los procedimientos literarios por medio de los cuales este dinamismo se forma en obra de arte. Entre tales procedimientos, uno de los que de un modo especial sirve para comunicar la energía de la obra de Cervantes es, a nuestro parecer, la representación rítmica de los elementos poéticos.

La forma exterior, Helmut Hatzfeld la ha estudiado con minuciosidad $y$ acierto ${ }^{1}$. Con lo que su excelente trabajo incluye sobre las manifestaciones lingüísticas del dinamismo cervantino, a saber, la repetición variada del mismo motivo --procedimiento por excelencia rítmico-, Hatzfeld ha dado un paso importante hacia una explicación del fenómeno.

Sin embargo, falta una explicación cabal del ritmo y del movimiento narrativo de la novela. Para que se lleve a cabo, partiendo de la relación entre significado y significante, desde la perspectiva de aquél a éste, es decir, de la forma interior ${ }^{2}$, se necesitaría, por lo menos, un estudio riguroso

1 Helmut HatzFel, El "Quijote" como obra de arte del lenguaje. Madrid, 1949. Traducción del texto original alemán "Don Quijote" als Wortkunstwerk.

2 En el complejísimo núcleo de elementos internos que constituyen la causa formal de la cristalización lingüística de la obra literaria, incluimos, arbitrariamente, la organización de estos elementos, desde que el escritor encadena las oraciones en párrafo hasta que, progresivamente a través de todo el proceso de gestación, quede plasmado el conjunto. Consciente o inconscientemente, el poeta tiene que solucionar estos problemas de organización antes de entrañar la concepción en su medio. Toda condición previa a la palabra la atribuimos a la forma interior.

Partiré, para formar este concepto, de la teoría de Dámaso Alonso en torno a la relación entre significado y significante. Ver su Poesía española. Madrid, 1957, páginas $19-33$. 
de los siguientes aspectos fundamentales: La manifestación rítmica del complejo temático; la disposición de la materia narrada, tanto en sus grandes rasgos a través de la obra como, más detalladamente, en partes representativas; la función de los personajes principales como seres que, pensándose a sí mismos, responden a las repetidas incitaciones externas con la consistencia variada de su ritmo personal; la cristalización estilística de la forma interna, con la mira puesta en el ritmo sensible. Dentro de estas categorías se debería trazar, sin incurrir en el simplismo de los que quijotizan a Sancho y sanchifican a don Quijote de un modo inequívoco, la trayectoria del héroe y la de su escudero, cuyo ritmo, al principio independiente del de don Quijote, se independiza parcialmente en la segunda parte. Además, sin olvidar nunca que la creación cervantina es una obra maestra de forma cómica, sería necesario estudiar las variaciones del punto de vista humorístico, las cuales abarcan toda la gama de lo cómico, desde la farsa más grosera hasta la risa más sublime. También habría que tener en cuenta el ritmo de los distintos puntos de vista de varias voces narradoras como dinámica de la retórica del arte de novelar.

Todo esto no puede caber dentro de las páginas de este trabajo. Nos limitaremos a las siguientes consideraciones : 1) Una breve reseña de las que, a nuestro parecer, soll las principales contribuciones críticas al estudio de nuestro asunto. 2) Alternancia de acción y pensamiento. 3) E1 ritmo de las aventuras. 4) Yausas en ei movimiento narrativo. 5) Variaciones de tempo y violentos contrastes barrocos. 6) E1 ritmo de motivos paralelos.

\section{Juicios críticos del dinamismo y ritmo del Quijote}

José Ortega y Gasset, al distinguir el nuevo modo de novelar cervantino del antiguo modo de novelar épico, fue quien, con más penetración que ningún crítico anterior, comprendió el principio que gobierna la forma del Quijote ${ }^{3}$. ¿En qué consiste la novedad de Cervantes? En que, en el

3 José Ortega y Gasser, Meditaciones del "Quijote", págs. 149-162. Es cierto, como dice Américo CaStro en El pensamiento de Cervantes, Madrid, 1925, pág. 77, que, desde el romanticismo alemán, la crítica se va enterando de que con el Quijote se crea la novela moderna: por su forma cómica (Herder); por la contraposición antitética entre la realidad y el sueño (Novalis); por el conflicto de la naturaleza y la razón contra la sinrazón (Bouterwerk). Pero lo que estos estudiosos indicaron de un modo general y parando mientes en la oposición sueño-realidad, Ortega lo desarrolla con mayor precisión y teniendo plena consciencia, por primera vez, de la novedad más significativa, que es la virtud de comunicar una impresión de lo inmediato. 
Quijote, se opone el devenir de personajes en pleno proceso de desenvolvimiento al aorismo épico, es decir, a la caracterización de seres heroicos, terminantemente definidos y acabados en el pasado. Con razón declara Ortega que la novela moderna es la contraposición deì género épico, siendo el tema de éste el pasado, y el de la novela, la actualidad, como tal actualidad. Más precisamente la impresión de lo inmediato, que Ortega llama lo actual, se produce oponiendo la voluntad individual a la sociedad: "Cuando el héroe quiere, no son los antepasados en él o los usos del presente quienes quieren, sino él mismo. Y este querer él ser él mismo es la heroicidad.)

Inevitable consecuencia de este querer ser individual frente a lo acostumbrado es la acción y la reacción conscientes del personaje cuyo criterio es la libertad ${ }^{4}$.

Once años después de la publicación de las Meditaciones del Quijote, Américo Castro, en El pensamiento de Cervantes ${ }^{5}$, secunda la opinión de Ortega y declara que, gracias a este vivir violentamente de don Quijote en su realidad, surge el nuevo género de la novela. Castro propone "seguir con alguna mayor precisión la trayectoria de semejante proceso en la mente de Cervantes", y logra su propósito con éxito notable, señalando los grandes rasgos del dicho proceso en la obra total del autor. Pero hasta 1947 el destacado cervantista, en el trabajo sobre la estructura del Quijote, con motivo del cuadricentenario del nacimiento de Cervantes ${ }^{6}$, no plantea con el debido rigor la fórmula básica del nuevo modo de novelar. En el Quijote, ciertos personajes, pero especialmente don Quijote, manifiestan su carácter reaccionando con continuo dinamismo a los continuos estímulos de la vida. "La vida de los personajes mayores creados por Cervantes -observa Castro- sería como el vértice en donde convergen una incitación venida de fuera y las acciones provocadas por aquella incitación”" ${ }^{7}$.

4 Según Lurs ROSALES, en su ingente y extraño libro de dos tomos, Cervantes y la Libertad, Madrid, 1960, la libertad es el tema capital del Quijote.

5 Américo Castro, El pensamiento de Cervantes. Madrid, 1925, pág. 34.

- Américo Castro, La estructura del "Quijote". Realidad, 1947, I, págs. 145-170. Para Castro este nuevo modo de novelar corresponde a un modo de ser por excelencia hispánico. Esto también ya lo había dicho ORTEGA : «Vida española, digámoslo lealmente, vida española, hasta ahora, ha sido posible sólo como dinamismo. Cuando nuestra nación deja de ser dinámica, cae de golpe en un hondísimo letargo y no ejerce más función vital que la de soñar que vive» (Meditaciones, pág. 85).

7 Castro, Estructura..., pág. 147.

19 
He aquí el principio interno de la estructura del Quijote. Ni Ortega ni Castro, ambos empeñados en captar el pensamiento de Cervantes, analizaron la materialización estilística de este principio.

Nos parece que quien con mayor éxito ha dado el primer paso en esta dirección es Helmut Hatzfeld. Su estudio del Quijote como obra de arte del lenguaje contiene un capítulo en que traza las manifestaciones lingüísticas de los móviles impulsores por los que la novela se desenvuelve en forma dinámica. "Y ya una rápida lectura de la novela da la impresión imborrable -declara Hatzfeld- de que en vez de un enlace tectónico de las aventuras entre sí, se trata de momentos espirituales en continuo intercambio (la cursiva es mía), enlace y oposición" ${ }^{8}$. Con razón se atiene Hatzfeld a términos musicales al analizar la temática (Leitmotive) reiterada, ya en tono mayor, ya en tono menor, ya con múltiples variaciones de tempo y de afectividad.

Hatzfeld comprende que, en el fondo, a pesar de cambiantes melodías, siempre late un motivo fundamental el de la misión caballeresca de don Quijote. Entre las variaciones lingüísticas de este motivo, aduce las que no demuestran más que sustitución de elementos verbales semejantes, las que amplían el concepto original, las que acentúan una nota particular como (amparar doncellas) y (socorrer viudas), dentro del tema general de "desfacer entuertos", las que lo anuncian con la fanfarria o escarnio del indicativo, o con el alarde o la ironía del sustantivo.

E1 motivo básico de la misión caballeresca de don Quijote es secundado por el de Dulcinea.

Apuntando a las alternancias que se producen por la operación de causa y efecto, Hatzfeld observa las oscilaciones quijotescas del sosiego a la cólera, y las sanchescas, del entusiasmo por su carrera escuderil, cuando le halaga la promesa de la ínsula, al desaliento, cuando le va mal.

Trazados estos y otros motivos, Hatzfeld declara que "la suposición de una arquitectónica fue rechazada desde un principio con razón” ${ }^{9}$. Pero. a la vez, insiste en que no por falta de una disposición arquitectónica carece el Quijote de una forma comprensible que "le hace ser distinto de las meras series de sucesos y episodios de la novela picaresca, así como también le distinguen de aquellas situaciones que se desenvuelven sin atención a una finalidad en la novela pastoril». El ritmo de este género, como

8 HatzFeld, El "Quijote"..., pág. 15.

9 HatzFald, El "Quijote"..., pág. 37. 
el de la novela de caballerías y el Persiles, según Hatzfeld "son absolutamente estáticos", por acatar Cervantes en estas obras una manera clasicista. Pero porque, en el Quijote, "le style c'est l'homme", sin el medio de una convención, "se da en esta novela un estilo netamente dinámico que... es, sin duda alguna, la expresión del ritmo de un motor lleno de vida, de un hombre al cual es inherente la energía de un inaudito movimiento palpitante e impulsivo" ${ }^{10}$. Como manifestaciones estilísticas de este dinamismo Hatzfeld trae a colación ciertos procedimientos, como, por ejemplo, la animación de objetos insensibles; la irrupción subjetiva del narrador que comunica su punto de vista, aportándolo a la aparente representación objetiva; la abundancia de ciertas fórmulas enfáticas como la geminación, las series asindéticas y sindéticas, y la acumulación de formas del verbo.

En otras partes del libro, notablemente en el capítulo sobre la antítesis, Hatzfeld da a entender, aunque no lo manifiesta expresamente, que la estructura del Quijote es rítmica. Lo que la denuncia como tal es la reocurrencia de motivos antitéticos. Falta, para hacer cabal este estudio, un análisis minucioso del movimiento sensible de trozos representativos. Esto lo emprende parcialmente Hatzfeld en las siete páginas dedicadas al cursus ${ }^{11}$.

Alternancia de acción y pensamiento

Si en el Quijote no hay enlace tectónico, ¿cómo cobra, en su totalidad, una forma orgánicamente estructurada? A nuestro parecer, el sistema de acciones y reacciones del héroe dinámico, cuya vida es (aquel constante desgarrarse de aquella parte de sí mismo rendida al hábito, prisionera de la materia) ${ }^{12}$, entraña la unidad oculta de la novela.

Creo que la alternancia de estas acciones y reacciones conscientes producen el ritmo fundamental. Como ya lo ha indicado Hatzfeld, el móvil impulsor de este dinamismo es la conciencia que el protagonista tiene siempre de su misión caballeresca. Al estudio que Hatzfeld ya ha hecho de este motivo repetido, propongo aportar algunas observaciones sobre un aspecto muy especial: 1a alternancia imbricada de las fases activas y reflexivas en el continuo devenir del héroe.

10 HatzFeld, El "Quijote".., pág. 278.

11 HatzFeld, El "Quijote"..., págs. 377-384.

12 OrTeGa, Meditaciones, pág. 187. 
La reflexión o, mejor dicho, la total reacción vital psíquico-reflexiva, sigue inevitablemente al choque sensible del héroe con el mundo que lo rodea. La fase reflexiva suele ser mucho más notable una vez que don Quijote y Sancho arrostran juntos sus aventuras ${ }^{13}$. Pero, aun antes de que Sancho una su destino al de su amo, éste hace constar a las claras la conciencia que tiene de sus móviles, tanto al obedecerlos en forma de asción como al justificar, en la fase reflexiva, lo que ha hecho según las nurmas de su mundo regulado. Haciendo, don Quijote obra con pleno conocimiento de causa; reflejando, expone la causa.

El proceso alternante que se acaba de señalar es una constante de la vida de don Quijote hasta que muere. Ya que analizar todas las ocurrencias del proceso equivaldría a una extensísima glosa de toda la acción principal, ha de bastar aducir unos ejemplos.

Uno de los sobresalientes, el de la aventura de los leones (II, 17), sirve como pocos para demostrar la actividad cognoscitiva de don Quijote, tanto durante la fase activa como en la reflexiva. Todos recuerdan los varios esfuerzos del leonero, don Diego de Miranda y Sancho, a través de unas cuatro páginas, para disuadirle de su temeraria empresa. Con tanto brío y tantas acertadas razones contesta a todas las repetidas amonestaciones y ruegos que, llevada a cabo la proeza, le parece a don Diego de Miranda, al repasar para sus adentros "las palabras y hechos» del hidalgo, que (era un cuerdo loco y un loco que tiraba a cuerdo", y "que lo que hablaba era concertado, elegante y bien dicho", aunque lo que hacía era "disparatado, temerario y tonton. He aquí, en el pensamiento de un observador en contacto inmediato con el héroe, una versión original de la declaración de Américo Castro sobre el carácter consciente del personaje cervantino que, dentro de la razón de su sinrazón, se piensa a sí mismo. Eñ la fase reflexiva, don Quijote, en una peroración inolvidable que concluye lo ya hecho y dicho frente a los leones, expone, en dos páginas de razonamientos grávidos, la justificación de su modo de ser. Ya no son sus palabras las impulsivas que lanza, con arrojada invectiva, durante los momentos de la incitación. Son las de un hombre que, conociéndose tanto a sí mismo como a la humanidad normal, acusa una porción pequeña de objetividad : "¿Quién duda, señor don Diego de Miranda —-dice-, que vuesa merced no me tenga en su opinión por un hombre disparatado y loco?

13 «Durmió Sancho aquella noche en una carriola, en el mesmo aposento de don Quijote, cosa que él quisiera escusar si pudiera porque bien sabía que su amo no le había de dejar dormir a preguntas y a respuestas... (II, 70). Este hacer preguntas y dar respuestas de don Quijote es lo que suele ocurrir después de las aventuras. 
Y no sería mucho que así fuese, porque mis obras no pueden dar testimonio de otra cosa. Pues, con todo esto, quiero que vuesa merced advierta que no soy tan loco ni tan menguado como debo de haberle parecido.) Luego ensalza, describiéndola, la vida intrépida, altruísta, liberal, cristiana, trabajosa e indómita de los de su casta. Termina defendiendo la valentía como virtud superior a la circunspección, ambas puestas entre los dos extremos de la cobardía y la temeridad, porque "ăntes se ha de perder por carta de más que de menos, porque mejor suena en las orejas de los que lo oyen "el tal caballero es temerario y atrevido" que no "el tal caballero es tímido y cobarde""). Así hubiera defendido en el foro su causa un senador romano.

Otro ejemplo capital que conviene aducir, por ser un ejemplo no de las más corrientes colisiones de violencia física, sino de un choque de personalidades, es el del encuentro con el eclesiástico antipático ${ }^{14}$ del palacio de los duques. Cuando, hablando don Quijote con la duquesa, el eclesiástico le oye decir de gigantes, follones y encantos, le insulta, llamándole "este don Quijote o don Tonto" y "alma de cántaro", y le pregunta quién le ha encajado en el cerebro que es caballero andante y que vence gigantes y prende malandrines. Don Quijote tiembla de pies a cabeza como azogado y ataca a su contrario, no con su fuerte brazo, "porque saben todos que las armas de los togados son las mesmas que los de la mujer, que son la lengua", sino con su propia lengua "en igual batalla" con su merced Primero lo aplasta con palabras ad hominem del todo merecidas. Luego, ateniéndose otra vez al inevitable auto-análisis, termina otra justificación de su vocación con las siguientes palabras, que ni el eclesiástico ni el mundo han podido negar: "Mis intenciones siempre las enderezo a buenos fines, que son de hacer bien a todos y mal a ninguno: si el que esto entiende, si el que esto obra, si el que desto trata merece ser llamado bobo, díganlo vuestras grandezas, Duque y Duquesa excelentes.)

14 La serie de "destos", usados despectivamente por el narrador al decirnos qué clase de sacerdote era el eclesiástico, creo demuestra que semejantes sujetos le inspiraban profunda antipatía a Cervantes: "La Duquesa y el Duque salieron a la puerta de la sala a recebirle, y con ellos un grave eclesiástico destos que gobiernan las casas de los príncipes; destos que, como no nacen príncipes, no aciertan a enseñar cómo lo han de ser los que lo son; destos que quieren que la grandeza de los grandes se mida con la estrecheza de sus ánimos; destos que, queriendo mostrar a los que ellos gobiernan a ser limitados, les hacen ser miserables; destos tales digo que debía de ser el grave religioso que con los Duques salió a recebir a don Quijote» (II, 31). 
Como estos ejemplos, muchos otros podrían demostrar nuestra tesis. Escogeré, casi al azar, dos del principio y dos del final del libro, terminando con el de su muerte consciente.

En I, 4, don Quijote, guiado por su criterio de justicia natural, socorre a Andrés y luego, estando ya solo, dirige su primer apóstrofe a Dulcinea. El apóstrofe es una defensa de lo que ha hecho.

Después del segundo encuentro, el de los mercaderes toledanos, cuyo mozo de mulas apalea a don Quijote, "viendo, pues [don Quijote], que, en efecto, no podía menearse, acordo de acogerse a su ordinario remedio, que era PENSAR en algún paso de sus librosı ( $(, 5)$. ¿Qué es lo que le da a don Quijote aliento en esta desgracia? Pensar en que había sido desgraciado también otro héroe de la caballería andante, a saber, el Marqués de Mantua.

En los capítulos 57 y $\mathbf{5 8}$ de la segunda parte observemos, por último, los siguientes ejemplos :

FASE ACTIVA

\section{FASE REFLEXIVA}

\section{La burla de Altisidora}

La burla de Altisidora, culminación de las experiencias avacías» de don Quijo. te en la casa de los Duques. Blanco de una serie de burlas calculadas, el caballero, en vez de tomar la iniciativa de marras, es víctima de la ajena. Como se verá por lo que dice en la fase reflexiva, el encierro le ha pesado (II, 57).
Al dejar la casa de los Duques, don Quijote celebra su recobrada libertad pensando no sólo en lo que significa para él personalmente ; piensa, además, en lo que significa para la humanidad en general.

Sancho aporta su propia reacción reflexiva en términos materialistas (II, 58).

\section{El encuentro con los labradores del retablo}

Los labradores descubren las imágenes que llevan a su aldea para hacer un retablo, to que suscita observaciones espontáneas sobre cada una de ellas por parte de don Quijote. Esta aventura pertenece a las placenteras, en que el estímulo psíquico suscita sólo una reacción verbal y no física. "Si esto que nos ha sucedido hoy -dice Sanchose puede llamar aventura, ella ha sido de las más suaves y dulces que en todo el discurso de nuestra peregrinación nos ha sucedidos (II, 58).
En una recapitulación quintaesencial del significado de su carrera caballeresca, don Quijote declara de qué modo se parece a los caballeros a lo divino", y de qué modo se distingue de ellos. Como si se diera cuenta de que las palabras de don Quijote entrañan el pro_ fundo significado de toda una vida consciente, el narrador nos dice que Sancho quedó de nuevo «como si jamás hubiera de haber historia en el mundo, ni suceso, que no lo tuviese cifrado en la uña y clavado en la memoria.... (II, 58). 
Al fin, el majestuoso fluir de una vida de acción y pensamiento desemboca en el mar sereno de la muerte, activo el pensamiento de don Quijote hasta el momento de expirar. Para demostrarlo, subrayaré, en una glosa de partes de sus últimas palabras, las que acusan la perseverante actividad de su facultad reflexiva. Le dice a su sobrina que tiene el juicio ya libre y que ya conoce los disparates de los libros de caballerías. Lamenta que no le quede tiempo para leer otros libros que sean luz del alma, y declara querer morir de tal modo que deje renombre de loco. "A las dichas razones -dice el narrador- añadió otras muchas tan bien dichas, tan cristianas y con tanto concierto, que del todo les vino a quitar la duda $\mathrm{y}$ a hacer creer que estaba cuerdo." Iuego hace su testamento, pero vive tres días más. El último, "después de recebidos todos los sacramentos y después de haber abominado CON MUCHAS Y EFICACES RAzONES de los libros de caballerías..., dio su espíritu...).

La perseverante actividad del pensamiento de don Quijote a través de su carrera es lo que impide que incurra en monotonía la serie consecuente de sus aventuras. Es cierto que nunca, menos hacia el fin de su carrera, nos cabe duda de que va a responder como quien es a las incitaciones que vienen de fuera, es decir, más o menos del mismo modo. Sin embargo, porque es un ser consciente, nunca son mecánicas, como las de los personajes-tipos con sus etiquetas o rótulos verbales, como los de varios de Dickens y, especialmente, Mr. Brooke de George Eliot en Middlemarch, "repetidor y nada más", según E. K. Brown ${ }^{15}$. "Nos reímos de Mr. Brooke - afirma Brown- porque lo que dice no se produce por la incitación que le hace hablar, sino por los moldes duros de su mente...) Bergson, tan enamorado de su teoría de la inflexibilidad como base de lo cómico, se equivocó al ver sólo rigidez en don Quijote. Ha comprendido mejor su carácter equívoco Erich Auerbach, el cual sostiene que el hidalgo responde mecánicamente sólo cuando se apodera de él su idée fixe. Libre de ella, su sensatez es admiitida y admirada por todo el mundo. No creo que ni aun don Quijote obseso sea un autómata que se pueda reducir a la categoría de un muñeco sorpresa. Es cierto que podemos anticipar cómo va a responder cuando se toca su punto flaco. "Solamente venía a perder los estribos... en tratándole de caballería" (I, 49), dice el cura. Sin em- 
bargo, la reacción determinada por la idea fija obedece normas de un sistema, aun cuando "lo que hacía era disparatado, temerario y tonto" (II, 53). Don Quijote dista mucho de ser "un repetidor y nada más", como Mr. Brooke; más bien responde a toda incitación de un modo consistente, sin duplicación mecánica. Así hay que comprender el parecer d $\epsilon$ don Diego de Miranda, a saber, que don Quijote "era un cuerdo loco y un loco que tiraba a cuerdo". Las palabras definitivas sobre su modo de ser las pronuncia el propio don Quijote, pensándose a sí mismo hasta el fin: "... cada uno es artífice de su ventura. Yo lo he sido de la mía; pero no con la prudencia necesaria) (II, 66).

No debemos de perder de vista tampoco otro aspecto de la vida de don Quijote que lo separa del autómata: su capacidad para cambiar. En la segunda parte, fuera de una notable excepción, la del barco encantado, ya no hay engaño a los ojos: ya no es castillo la venta; lo imaginado don Quijote lo ve soñando en el profundo sueño de la Cueva de Montesinos (II, 25); ya no es tan impulsivo, "reportándose lo mejor que pudo" cuando quiso decirle al caballero del bosque que mentía, "y ya tuvo el mentís en el pico de la lengual; frente a los brazos levantados de los recitantes que conducían el carro de la muerte, don Quijote, con insólita circunspección, "pasóse a pensar de qué modo los acometería con menos peligro de su persona) (II, 11); ya, casi al fin, la circunspección se hace, patéticamente, miedo, temiendo don Quijote, en la casa de don Antonio Moreno, que, si iba a caballo a pasear la ciudad, "le habían de perseguir los muchachosn (II, 62), y también, ya casi terminada la novela, parece increible que se niegue a pronunciar un fallo para lucir su ingenio y exhibir su elocuencia cuando, al pedirle Sancho que adjudique el caso del corredor gordo y el delgado, contesta que no está "para dar migas a un gato", según traía "alborotado y trastornado el juicio» (II, 66).

Movimiento narrativo: variedad de las aventuras

Cervantes evitó la uniformidad enfadosa que pudo producirse por la serie de aventuras afines variándolas de muchos modos. Sin semejante variación, un escritor menos genial hubiera incurrido en monotonía al ensartar las aventuras que se suceden con tanta rapidez en los primeros 24 capítulos de la primera parte. Trece de los encuentros en estos capítulos estallan en violencia física. ¿Cómo los diferencia el autor?

Primero, mezclando, con las derrotas del hidalgo, cómicas victorias falsas. En el gráfico que se pone a continuación (los puntos altos se- 
ñalan triunfos y los bajos derrotas) se puede ver claramente la acertada distribución de ambos:

$\begin{array}{llllllllllllllllllllllll}2 & 3 & 4 & 5 & 5 & 7 & 9 & 1 & 11 & 12 & 13 & 14 & 15 & 15 & \pi & 18 & 0 & 20 & 21 & 22 & 23 & 24\end{array}$

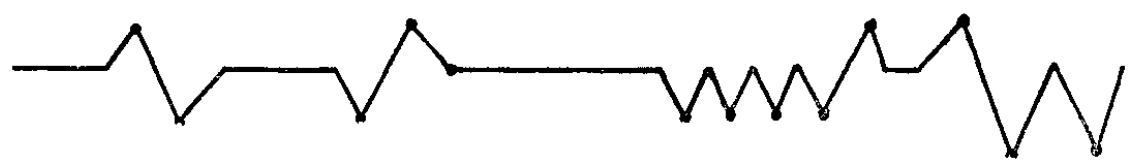

Las cuatro "victorias" se pueden dividir, graciosamente, de un modo bimembre: triunfa de los arrieros que interrumpen su velar de armas en la primera venta (cap. 3) y del valiente vizcaíno (cap. 9) porque le favo. rece la suerte para que empiece su carrera con pie derecho; triunfa de los sacerdotes encamisados que, de noche, conducen un cuerpo muerto rumbo de Segovia (cap. 19), y triunfa del barbero del yelmo de Mambrino, porque el enemigo es manso y está desprevenido (cap. 21).

Basta enumerar las ocho derrotas para demostrar su heterogeneidad: la del mozo de mulas de los mercaderes toledanos, nue lo apalea porque el hidalgo, enfurecido por las irónicas pullas de uno de sus amos, lo ataca (cap. 4); la de los molinos de viento, que es ejecutada por un contrario insensible (cap. 8); la de los desalmados yangüeses por culpa de (Rocinante) (cap. 15); la del arriero, amante de Maritornes, por un engaño de sabor bocacciano (cap. 16); la del cuadrillero de la segunda venta, que le da un candilazo a don Quijote porque éste se indigna cuando aquél no le da tratamiento (cap. 17); la de los pastores de ovejas, en rue los enemigos imaginados son animales indefensos (cap. 18); la de los galeotes, que le dan las gracias por liberarlos apedreándolo (cap. 22), y. al fin de la serie, la de Cardenio, contraparte sentimental de don Ouijote, por una diferencia de opinión sobre el carácter de la reina Madásima (capítulo 24).

I a variedad es la de la naturaleza misma, cuyos fenómenos renetidos. como el de la luminosidad cambiante de una radiante mañana de primavera o los movimientos de una tempestad, nunca se duplican.

Pero, además, despunta la ordenación del arte.

Ya despunta, por ejemplo, en la disposición de la materia, la incidencia paralela, por la cual, ya sea en forma de paralelismos correspondien. tes o antitéticos, se repiten, con variaciones, temas centrales. En la seric de 24 capítulos que hemos examinado, se destacan dos parejas de incidentes gemelos: la de la intervención de don Quijote en las relaciones del muchacho Andrés y su amo Juan Haldudo (cap. 3), que corresponde a la 
liberación de los galeotes (cap. 22), y la de la aventura de los molinos de viento, que corresponde a la de los ejércitos de ovejas (cap. 18). En la primera se resalta el admirable, pero contraproducente, criterio de la justicia natural que rige al hidalgo, y en la segunda el engaño a los ojos, cuyas consecuencias desastrosas don Quijote, introducido otra vez en la realidad, después de su no admitido error, las atribuye a obra de encantadores.

No hay que dejar de notar que, para intensificar el impacto de la serie, Cervantes asciende al punto culminante, acentuando forte, el tema que antes presentó piano. E1 tema de la aventura de los galeotes es una elaboración del encuentro con Andrés y Juan Haldudo, y el altisonante virtuosismo del hidalgo cuando describe los imaginados ejércitos dirigidos por Pentapolín del Arremangado Brazo y Alifanfarón de la Grande Isla Trapobana es un sonoro crescendo cómico de clarines y trompetas, el primero de la sinfonía novelesca.

Lo que hemos analizado caracteriza toda la novela. Es la gradación. Veremos en su lugar cómo la carrera de don Quijote asciende a un clímax, y, a partir del clímax, desciende hasta que muere.

Pausas en el movimiento narrativo

No son siempre los arreos de don Quijote las armas ni su descanso el pelear. De vez en cuando se detiene para descansar. Ya hemos visto cómo, en la primera y segunda salidas, se lanza a una serie rápida de encuentros violentos desde el altercado con los arrieros hasta la estupenda batalla con el vizcaíno. i Ya bastan los tajos y reveses! Por eso escuchamos con redoblado deleite el discurso de la Edad de Oro que don Quijote pronuncia para los cabreros. Estos cabreros comparten con él su humilde comida; son los primeros que lo tratan bien. Su existencia es un remanso del río turbulento de la vida; su sencillez, domicilio de la inocencia. E1 episodio de los cabreros es una pausa de transición que nos prepara para suspirar en el ambiente pastoril del desesperado Grisóstomo y la independiente Marcela en el capítulo que sigue.

A través de la novela los principales intermedios deleitosos, fuera del ya comentado, son : el del discurso de las armas y las letras (I, 37); la historia de la hermosa Leandra (I, 51); la visita de don Quijote a la casa de don Diego de Miranda (II, 18); las bodas de Camacho (II, 20, 21); la fingida Arcadia (II, 58).

Dieciséis capítulos después del encuentro placentero con los cabreros, de $I, 11$, los cuales lo escucharon con la boca abierta, "movido - nos 
dice Cervantes- de otro semejante espíritu que el que le movió a hablar tanto como habló cuando comió con los cabreros") (I, 37), pronuncia su segundo discurso extenso, el de las armas y las letras. Este, como el primero, que fue precedido por un suceso halagüeño, tiene por antecedente el feliz desenlace de las historias de las parejas Cardenio-Iuscinda, don Fernando-Dorotea. E1 regocijo general inclina a todos a escucharlo con gusto. Especialmente a los caballeros, "a quien son anejas las armas", que "le escuchaban de muy buena gana" (I, 37).

E1 tercer intermedio mitiga la melancolía de los últimos tres capítulos $(\mathrm{I}, 50,51,52)$ de la primera parte. Al rogarle al cabrero Eugenio que cuente su historia, don Quijote, acaso en función de portavoz de Cervantes, le asegura que lo escuchará “de muy buena gana, y así lo harán todos estos señores, por lo mucho que tienen de discretos y de ser amigos de curiosas novedades que suspendan, alegren $\mathrm{y}$ entretengan los sentidos, como, sin duda, pienso que lo ha de hacer vuestro cuento" (I, 50). ¿No indica aquí Cervantes una de las funciones de la deleitosa materia intercalada? La vida no debe ser un continuo hacer, ni cuando la fortuna frunce el ceño conviene estarse cabizbajo sin acoger ocasiones que suspendan, alegren y entretengan. Obligado a volver a su casa por la fuerza, soltado de la jaula como se suelta sólo provisionalmente a un reo de sus prisiones, don Quijote, al fin de esta primera parte, con la no disminuída salud espiritual del sujeto capaz de alegrarse hasta cuando le va mal, se dispone a escuchar embelesado un cuento pastoril. $Y$ nosotros con él, porque de vez en cuando es deleitoso acogerse del sol ardiente a la sombra.

La intercalación deleitosa más extensa, la de las bodas de Camacho (II, 21, 22), está colocada en el centro de la novela (los 126 capítulos de las dos partes forman una unidad, sin duda), como para celebrar los dos mayores triunfos de don Quijote: el dudoso contra el caballero de los espejos (II, 14) y el verdadero, aunque paródico, contra los leones (II, 17). Los dos capítulos de las bodas, todo juego, sirven, además, para despejar el alma en la esfera de la comedia pura, antes de que empecemos a compartir con el héroe su vergüenza y su descenso en el palacio de los Duques y en Barcelona. Este episodio, de exuberancia rabelesiana y de graciosa travesura, ilumina al de la Triste Figura en la mitad de su carrera. "Gozac la ocasión', parece decirnos el autor a su héroe y a sus lectores, "porque en la vida sólo una vez acaso le sea dado al hombre el limpio regocijo que únicamente los dioses (que no saben nada de la tribulación humana) disfrutan en una continua fiesta allá en su Olimpon.

En el cielo tempestuoso de la carrera de don Quijote, desde el amane- 
cer de su locura hasta el ocaso de su restitución, con la muerte, a la cordura, se abre una clara brecha a mediodía.

No le es ajeno el espectáculo jocoso, porque, desde el principio, declara estar por el amor contra el interés, abogando por el amante pobre; y, burlado el novio rico por la treta de su rival, don Quijote defiende a éste, declarando que "el amor y la guerra son una misma cosa), y que "así como en la guerra es cosa lícita y acostumbrada usar de ardides y estratagemas para vencer al enemigo, así en las contiendas y competencias amorosas se tienen por buenos los embustes y marañas que se usan para conseguir el fin que se desea...) (II, 21). Don Quijote, pues, arrogándose el papel de árbitro en cuestión de amor, proclama la validez del lema "amor es todo enredos".

¿Quiénes son los grandes amigos de don Quijote? Los amantes. "Grandes fueron y muchos los regalos que los desposados hicieron a don Quijote, obligados de las muestras que había dado defendiendo su causa..." (II, 22).

Amenizados por la traviesa luz de la alegría, los capítulos dedicados a las bodas de Camacho se destacan como el claro más notable en el medio del cuadro cervantino. Sólo una vez más gozamos de la risa juguetona de la comedia de retozos, cuando don Quijote y Sancho intervienen en la contienda de los albaceteños rebuznadores y el pueblo vecino que se burla de ellos. Entre el claro de las bodas de Camacho y el de esta zumbona sátira del orgullo cívico, media el oscuro de la profunda cueva de Montesinos. Hasta ahora, a través de 79 capítulos (I. 52; II, 27), los contrastes de luz y sombra han sido brillantes, y los nubarrones que ocultan el sol han sido pasajeros. Pero, después de volver una vez más a las andadas con la aventura del barco encantado - la única en el segundo Quijote en que el engaño a los ojos es inequívoco-, a través de los 44 capítulos restantes, las sombras son las que anuncian la noche fría y la luz se enturbia de crueldad por las vergonzosas burlas en el palacio de los Duques y por el espíritu vengativo de Sansón Carrasco. Como en el Quijote nada es simple, no se puede negar que, de vez en cuando, aun cuando va para abajo, la buena voluntad no le sonría a don Quijote, como cuando se encuentra con los labradores de los santos (II, 58) - según Sancho, la más dulce de todas las aventuras-, o con Roque Grinart, quien lo saluda como hermano (II, 60); o se hospeda en la casa de don Antonio Moreno, el cual sí le sigue el humor con intención burlona, pero de un modo más o menos benévolo.

$\mathrm{Y}$ en su tercer contacto con el mundo pastoril - los de la primera parte son el episodio Grisóstomo-Marcela y el de Leandra-, el de la Ar- 
cadia fingida, los pastores y pastoras honran a don Quijote dándole el primer lugar en las mesas puestas, "ricas, abundantes y limpias" (II, 58). Esstos pastores, pues, tanto como Roque Guinart y don Antonio Moreno, son buenos con don Quijote. Sin embargo, contra la movilización total, prolongada e inexorable del sistema de burlas engendradas por la ociosidad de los Duques, los raros actos de bondad de otras personas sólo momentáneamente iluminan con luz patética el rostro amarillo del caballero.

La repetición de motivos con variaciones y las distintas circunstancias de su ocurrencia aportan su ritmo al de la creación total, la cual se desenvuelve en forma de entretejedura de temas. Por tercera y última vez, don Quijote, al encontrarse con los pastores de la fingida Arcadia, aprovecha la ocasión para pronunciar un discurso de sobremesa, frente a un auditorio a quien inspira simpatía. Esta vez el discurso, sobre la ingratitud, es brevísimo, pero basta para concluir el ciclo rítmico y para que oigamos lo que E. M. Forster llama "singing in the halls of fiction".

La brevedad del último episodio pastoril corresponde a lo fugaz de los postreros momentos tranquilos del caballero. Su fugacidad se resalta brutalmente por un cambio repentino, el de la avalancha taurina. No bien se despide de los pastores cuando desciende, sobre él y Sancho, una estampida de toros, "dando con todos ellos en tierra, echándoles a rodar por el suelon (II, 58). En la fase reflexiva de este vergonzoso suceso, don Quijote dice, con amargura, "al cabo, al cabo, cuando esperaba palmas, triunfos y coronas, granjeadas y merecidas por mis valerosas hazañas, me he visto esta mañana pisado y acociado y molido de los pies de animales inmundos y soeces») (II, 59).

Nueve capítulos más tarde el motivo se repite: otra vez un preludio tranquilo precede a otra estampida. Pasando otra vez por el sitio en donde había dado con los pastores de la fingida Arcadia, don Quijote sueña con la vida pastoril que ha de llevar durante el año de recogimiento impuesto por los términos de su derrota en manos del caballero de la Blanca Luna. Mientras él y Sancho discurren, desciende sobre ellos una inmunda piara de más de 600 cerdos, "deshaciendo las trinchas de Sancho y derribando no sólo a don Quijote, sino llevando por añadidura a "Rocinante» (II, 68).

Este, uno de los más vergonzosos ultrajes que sufre don Quijote, cierra otro ciclo rítmico, el de sus cuatro encuentros con animales: 1), con los dos ejércitos de ovejas (I, 18); 2), con los leones (II, 7); 3), con los toros (II, 58), y, al fin, 4), con los cerdos (II, 68). Cada uno de ellos funciona como correlativo estructural. El primero es típico del invencible arrojo y optimismo inicial de don Quijote al principio de su carrera, porque, aunque le dejan molido los pastores, no hace la menor mella su de- 
rrota en su ánimo; el segundo señala la etapa más halagüeña de su vida, porque su legítimo triunfo secunda la dudosa victoria que tuvo contra el Caballero de los Espejos, que lo precede. La aventura de los leones también sirve de antecedente glorioso a la intervención más positiva de su vida, a saber, la que lleva a cabo como árbitro en las Bodas de Camacho; $y$, al fin, el ultraje de los toros que lo pisan y de los puercos que lo huellan corresponde al desenlace melancólico de su carrera.

Variaciones de tempo $y$ violentos contrastes barrocos

A las variaciones de tensión afectiva - ninguna de ellas tan violenta como las últimas dos que mencionamos- corresponden cambios de paso narrativo.

Huelga decir que el movimiento cinético no puede menos de ser más rápido cuando la acción es violenta y más lento cuando la acción es placentera, siendo la excepción el allegro de estrepitosas escenas festivas. Cuenta la regla tanto como la excepción en la serie de contrastes, los cuales, analizados desde otro punto de vista, ejemplifican también cambios cinéticos del progreso narrativo. Los cambios son: de la violencia de la aventura del vizcaíno ( $I, 9,10)$, a la escena pacífica de los cabreros (I, 11); de la batalla de los cueros de vino (I, 35), a la regocijada reconciliación de dos parejas de amantes (I, 37); del triunfo de don Quijote contra el Caballero de los Espejos y su atrevimiento con los leones, a las bodas de Camacho. En los otros dos casos, uno al fin de la primera parte y otro al fin de la segunda, la fase tranquila es anterior: en I, 51, don Quijote escucha en paz el cuento pastoril narrado por Eugenio y, luego, le remacha las narices cuando, al fin del cuento, el cabrero, enterándose de que el hidalgo se tiene por caballero andante, dice que debe de tener vacíos los aposentos de la cabeza. Y al fin, en II, 59, no bien se despide don Quijote de los pastores de la fingida Arcadia, desciende sobre él y Sancho la mencionada estampida de toros.

Nos parece que son formalmente significativos los f́ltimos casos de alternancia brusca, porque las abruptas transiciones de la tranquilidad efímera al desquiciamiento grosero resaltan el descenso del héroe. Antes, altas circunstancias precedían y sucedían a las pausas deleitosas: el discurso de la Edad de Oro, entre un triunfo y una historia sentimental; el de las Armas y las Letras, entre problemas de amor felizmente resueltos y la gesta heroica del capitán; las Bodas de Camacho, entre dos mayores triunfos, y su misión caballeresca, en el sueño de la Cueva de Montesinos. Pero, al fin de su carrera, el dulce encuentro con los labradores 
de los santos, al que sin interrupciọn sucede el episodio arcadiano, tiene por antecedentes la burla de Altisidora y, por secuela, el estropicio de animales inmundos. Y cuando, por vía de remate, se repite el motivo, el recuerdo pastoril se verifica entre uno de los momentos más desanimados de la vida de don Quijote (cuando se niega a adjudicar el caso de los corredores) y el ultraje cerdoso.

El ritmo de motivos paralelos

Conviene distinguir entre el paralelismo de bimembración simple, cuyos elementos correspondientes o contrastantes se disponen de un modo tectónico, y el complejo de una construcción multimembre, cuya iteración es incidencia de una serie de motivos.

Los paralelismos del Quijote pertenecen a la segunda categoría.

Uno de los ejemplos más notables del paralelismo clasicista de la literatura hispánica es el del Reino Interior, de Rubén Darío. En este fresco alegórico, la figura central de la Infanta, el alma del poeta, mira estremecida, desde la torre del palacio paterno, el desfile, por el lado derecho de un camino de color de rosa, de las siete virtudes cardinales $y$, por el izquierdo, el de los siete pecados capitales. En el centro de este cuadro un encabalgamiento ${ }^{16}$, a $\mathrm{mi}$ parecer también peregrino en nuestra literatura, divide en dos partes iguales las equilibradas partes de un perfecto sistema de báscula. Essta disposición de elementos produce una forma estática de dos contrapartes.

En la novela dinámica de Cervantes las dos ocurrencias de un motivo paralelo suelen formar parte de una sarta de ocurrencias afines, como ya hemos observado al señalar la variedad del movimiento de los primeros veinticuatro capítulos de la primera parte. Conviene aducir manifestaciones adicionales de este procedimiento tan importante en la orquestación rítmica de la obra total.

En la contextura de acciones que constituyen la principal y las secundarias, el asunto que más se repite es el de los amores de una serie de parejas. Entretejidas a la historia del amor platónico de don Quijote, se narran, además, las historias de Grisóstomo y Marcela, de Cardenio y Luscinda, de don Fernando y Dorotea-Micomicona, la de Anselmo y Camila, la del Capitán Cautivo y Zoraida, la de don Luis y doña Clara, la

16 Se encabalgan la raíz adjetival y la desinencia adverbial de una sola palabra:

Al lado izquierdo del camino y paralelamente, siete mancebos - oro, seda, escarlata... 
de la hermosa Leandra y Vicente de la Rosa, la de Basilio y Quiteria, la de Durandarte y Belerma, la de la Princesa Antonomasia y Clavijo, la de Tosilos y la hija de doña Rodríguez, la de Claudia Jerónima y Vicente Torellas y, al fin, la de Gaspar Gregorio y Ana Félix.

Se podrían añadir, a éstas, otras accesorias: en la aventura imaginada del lago de pez, la de los amores de don Quijote y la hija del emperador que se prenda de él (i esta sola vez olvida a Dulcinea !); la de la pastora que persigue al pastor que la ha abandonado, en la conseja interminable de las trescientas cabras que Sancho le cuenta a su impaciente señor; la de Clara Perlerina y el hijo de Miguel Turro, y, al fin, la de doña Rodríguez y el escudero.

Al enumerar las historias principales no he distinguido entre las que se presentan como verdaderas y las que se inventan para burlar a don Quijote; entre las que vemos desenvolverse directamente y las contadas por un personaje; entre las que están narrativamente enlazadas con la acción principal y las dos que son intercalaciones independientes. No he distinguido entre ellas adrede, aunque sólo por un momento, para subrayar tres cosas: que en el Quijote se confunden la experiencia literaria y la de la vida; que las historias inventadas, engañando a don Quijote con su verdad fingida, cobran, por la maestría del narrador, la autenticidad de la vida misma, y que las dos intercalaciones, la del Curioso Impertinente y la del Cautivo, por poco defendibles que sean como eslabones de la continuidad narrativa, pertenecen, y mucho, al complejo temático de la obra.

Pero distinguiéndolas todas, como es debido, para determinar la función formal de los distintos modos de presentarlas, hay que decir que las directamente presentadas, incluso una de las dos intercalaciones mencicnadas, sirven para oponer la experiencia posible en el mundo de las realidades inmediatas de personas normales a la experiencia ideal que es posible sólo en la experiencia de un loco. (E1 caso excepcional es el de Anselmo, tan loco como don Quijote, aunque en sentido diametralmente opuesto.) Al contrario del amor casto y paciente de don Quijote, los de los otros enamorados son los urgentes de las crisis sentimentales y pasionales del mundo corriente: de las Marcelas que no se sienten obligadas por lástima a ceder al amor desesperado de los Grisóstomos; de los Cardenios que no tienen la debida confianza en sí mismos y se desesperan sin suficiente razón; de las Doroteas cuya razón de amor lo vence todo; de los jovencitos que abandonan la casa paterna para estar cerca de la niña de los primeros amores; de los soldados, lejos de su patria, que se enamoran de extranjeras; de las chicas que no pueden resistir un uni- 
forme de soldado y especialmente si este soldado puede hacer hablar a una guitarra y componer romances; de las desposadas por interés que, en el último momento, rechazan al novio rico por el rival pobre; de las que matan por celos.

La función formal de los distintos modos de presentar las acciones que hemos enumerado está determinada por la actitud del hablante básico, actitud que, a su vez, determina lo que I. A. Richards denomina (tono", es decir, la relación que el autor establece con su lector. Esta actitud es lo que Wayne $\mathrm{C}$. Booth llama la retórica del arte de novelar. La retórica del foro es el arte de la elocuencia, cuyo propósito es persuadir al oyente para que comparta el punto de vista del orador. No menos que a éste le conviene al novelista inclinar a su lector al suyo. Pues bien : a Cervantes, por medio de su segunda voz, Cide Hamete Benengeli, le convino presentar las acciones de Cardenio y Luscinda y de Dorotea y don Fernando desde el punto de vista del narrador omnisciente para que formaran un contraste directo con la historia de don Quijote, siendo la contraposición la del tono mayor de amores felizmente llevados a cabo frente al tono menor de un amor que es posible sólo en el corazón del protagonista.

Cuando el punto de vista es el de un hablante interesado, a saber, el de uno de los personajes, el autor, por medio de este personaje, pretende inclinarnos a su punto de vista especial. Así es que cuando Dorotea, fingiendo el papel de Micomicona, improvisa la graciosa historia de sus tribulaciones para que don Quijote la socorra, ella transmite el punto de vista del narrador, que quiere que nos riamos con él. Y lo mismo vale en cuanto a la fabricación de la Dueña Dolorida cuando inventa la historia de la Princesa Antonomasia y Clavijo. Estas historias, separadas por cincuenta capítulos, forman uno de los principales paralelismos antitéticos de la obra, y su efecto cómico depende, en parte, del modo de presentarlas, por medio de un hablante de espíritu burlón.

Las variaciones del punto de vista son procedimientos rítmicos propios del arte de novelar, de los cuales se vale en sumo grado Cervantes y que merecen un estudio especial, que no podemos arrostrar en esta ocasión. Basta señalar la función estructural de los puntos de vista mencionados. Lo que comparten la burla de Dorotea y la de la Condesa Trifaldi como burlas paralelas es, básicamente, la intención cómica. Ambas inventan sus historias para engañar a don Quijote. El asunto de las dos fabricaciones es el mismo: la situación indefensa de una dama cuitada a quien sólo don Quijote puede socorrer. La gran diferencia es la que, como veremos, importa a las fases distintas de la carrera de don Quijote, la ascendente y la descendente, siendo la burla de Dorotea bien intencionada 
y la de la Dueña Dolorida parte de la serie de las crueles que se llevan a cabo en el palacio de los Duques ociosos. La Trifaldi no tiene más propósito que divertirse, con los Duques, a expensas del deslustrado hidalgo. De otra parte, la risa de Dorotea, secundada por la del bueno del cura y el barbero, es comparativamente benévola, y la muchacha no lleva a cabo su engaño sólo para divertirse, sino para lograr que el hidalgo vuelva a su casa para curarse.

Precisando el enfoque, observemos cómo, dentro de la forma paródica de las dos historias - ambas son parodias de la situación típica de la dama desdichada que en libros de caballerías es víctima de un gigante-, el plano en que obra la princesa Micomicona es mucho más elevado que el de la princesa Antonomasia. Micomicona, proyección de Dorotea, es una niña romántica que huye aterrada de un monstruo que la persigue; Antonomasia es una hembra vulnerable de un mundo desvalorizado en que hasta las princesas, por entregarse clandestinamente a las importunidades de mozos ordinarios, tienen que casarse por fuerza.

No nos parece caprichoso concluir que la contraposición románticovulgar que he señalado corresponde a las dos fases de la trayectoria de don Quijote. Hasta II, 17, se mantiene en la fase equívocamente ascendente de su carrera, la que culmina con su triunfo en la aventura de los.leones. Conviene a esta fase positiva que el engaño que se trama para ayudarìe sea delicado y que lo lleve a cabo una muchacha encantadora, cuya voz, al improvisar su gracioso cuento, es un trino de ave canora. De otra parte, conviene, al contrario, que, en la fase descendente de su carrera que empieza en el palacio de los Duques, engañado don Quijote sin justificación moral, trocada su armadura de caballero por traje cortesano, convertido el caballero andante, a pesar suyo, en caballero de a pie quedo, encerrado en su cuarto por la vergüenza de sus medias con los puntos sueltos, conviene, decimos, que a este pobre hidalgo tan venido a menos le engañe una dueña barbuda que grazna como cuervo al contar la historia de la chica preñada. Esta segunda ocurrencia del motivo es muy divertida en sí. La parodia deleitaría aun sin que recordáramos la primera ocurrencia. Pero modificada por el primer suceso paralelo, el segundo cobra, en el conjunto, una virtud formal de que carecería aparte. En la primera parte, violas y violínes presentan, allegro, el tema Micomicona. Su variación, el tema Antonomasia, lo presentan, scherzzando, sacabuches lascivos. Ambos son un comentario del tema central. Denominamos al uno $\mathrm{y}$ al otro "correlativo estructural».

En conclusión: El principio de la estructura del Quijote es el dinamismo de los principales personajes cervantinos, especialmente, por su- 
puesto, don Quijote. Inevitable consecuencia de su querer ser individual frente a lo acostumbrado son las acciones y reacciones conscientes en fases consecuentes de acción y razonamiento vital. A través de su trayectoria ascendente y descendente don Quijote obra de este modo, aportando a la novela su ritmo básico. Algunos de los aspectos de este ritmo que hemos tratado de exponer son, además de la fundamental alternancia de las fases activas y reflexivas que hemos mencionado, la variedad de motivos afines en el movimiento narrativo, la contraposición de triunfos y de derrotas en la serie de aventuras quijotescas, pausas en el movimiento narrativo, variaciones de tempo y violentos contrastes barrocos $\mathrm{y}$, por último, el ritmo de motivos paralelos. Estos no forman la geminación simple de dos contraparies sin modificantes intermedios, sino la de una repetición incidente a una serie de motivos afines.

Eddund de Chasca 